Reprod. Nutr. Dévelop., 1986, 26 (1 B), 373-374.

\title{
Biochimie clinique de l'intoxication naturelle par la sporidesmine chez les moutons Manech du Pays Basque
}

\author{
J. P. BRAUN ( $\left.{ }^{1}\right)$, P. BEZILLE $\left({ }^{2}\right)$, J. LE BARS $\left({ }^{3}\right)$, M. BONNEFOI $\left({ }^{1}\right)$, G. SAWADOGO $\left({ }^{1}\right)$
}

avec la collaboration technique de Marie-France PÉREZ.

(1) Laboratoire associé I.N.R.A. de Toxicologie Biochimique et Métabolique.

(2) Laboratoire de Pathologie du Bétail, E.N.V., 31076 Toulouse, France.

(3) Station de Pharmacologie-Toxicologie I.N.R.A., 31000 Toulouse.

Summary. Sporidesmin intoxication in Manech sheep of southwestern France has been demonstrated. It induced very severe liver damage in sheep showing cutaneous symptoms of facial eczema and increases of serum GGT, TGO, bilirubin and cholesterol. Moreover, many animals of the same flock without skin symptoms also exhibited serum biochemical disturbances.

L'eczéma facial est une affection bien connue dans divers pays comme l'Australie, la Nouvelle-Zélande, l'Afrique du Sud, le Texas (Atherton et al., 1974) ou I'Uruguay (Riet et Dias, 1974). Ce n'est que très récemment qu elle a été identifiée chez des moutons dans le sud-ouest de la France en 1982 (Bézille et al., 1984). Les symptômes cutanés de la maladie sont ceux d'une photosensibilisation secondaire à d'importants désordres hépatiques provoqués par les Sporidesmines.

Nous rapportons ici les principales modifications de la biochimie sérique de moutons Manech à l'occasion d'un nouvel épisode d'eczéma facial, à l'automne 1984.

Matériel et méthodes. Les observations ont été effectuées au Pays Basque, chez des agnelles de race Manech âgées de 7 à 9 mois, élevées sur des prairies naturelles. Les symptômes sont apparus en Septembre 1984 après une période de pluies abondantes suivant une longue sécheresse estivale. Parmi les 26 agnelles de 2 exploitations voisines, 9 présentaient une photosensibilisation et 17 étaient apparemment indemnes. Les animaux témoins sont des agnelles du même âge élevées dans des conditions identiques dans un élevage indemne voisin.

Les analyses du sérum des animaux ont été effectuées dans les $24 \mathrm{~h}$ suivant le prélèvement. Il a été réalisé un bilan biochimique large (SMAC Technicon).

Résultats et discussion. Les témoins étant aussi semblables que possible aux animaux des exploitations atteintes, seule l'évolution de l'intoxication peut rendre compte des modifications observées. Les résultats confirment les précédents (Bézille et al., 1984). Comme on peut le voir dans le tableau 1, tous les animaux cliniquement malades présentaient de très fortes altérations biochimiques. Par ailleurs, chez les agnelles ne montrant aucun symptôme, on a pu observer d'importantes perturbations de la biochimie sérique chez 10 sujets sur 17.

D'autres modifications biologiques (élévations du fer sérique et diminutions de l'albumine, des triglycérides et de l'urée sériques) ont également été notées. L'ensemble révèle : (1) une très forte cytolyse dont témoignent les élévations 
TABL. 1. - Principales variations de la bilirubine $(\mu \mathrm{mol} / \mathrm{l})$, du cholestérol $(\mathrm{mmol} / \mathrm{l})$ et des enzymes sériques (U/I) chez des agnelles Manech témoins (6), cliniquement atteintes d'eczéma facial (9), cliniquement indemnes avec (10) ou sans (7) altérations notables de la biochimie sérique. Les résultats (moyenne \pm écart-type) sont comparés par le test de Student aux moyennes des témoins $\left.1^{*}: P<0,05 ; * *: P<0,01 ; * * *: P<0,001\right)$.

\begin{tabular}{lcccc}
\hline & Témoins & Malades & $\begin{array}{c}\text { Non malades } \\
\text { GGT }>200 \mathrm{U} / \mathrm{I}\end{array}$ & $\begin{array}{c}\text { Non malades } \\
\mathrm{GGT}<200 \mathrm{U} / \mathrm{I}\end{array}$ \\
\hline PAL & $156 \pm 49$ & $656 \pm 272^{* * *}$ & $399 \pm 279$ & $161 \pm 33$ \\
Bilirubine & $1,2 \pm 0,4$ & $13,3 \pm 6,0^{* * *}$ & $(0$ à 19$)$ & $2,4 \pm 0,5$ \\
TGP & $15 \pm 3$ & $25 \pm 11^{*}$ & $5 \pm 4^{* *}$ & $12 \pm 6$ \\
TGO & $113 \pm 13$ & $(161 \pm 1470)$ & $203 \pm 84^{*}$ & $206 \pm 144$ \\
GGT & $66 \pm 8$ & $1964 \pm 717^{* *}$ & $922 \pm 487^{* *}$ & $117 \pm 45^{*}$ \\
Cholestérol & $2,62 \pm 0,18$ & $9,11 \pm 2,61^{* *}$ & $3,95 \pm 1,79$ & $2,79 \pm 0,16$ \\
\hline
\end{tabular}

PAL : Phosphatases alcalines (EC 3.1.3.1) ; TGP : Alanine aminotransférase (EC 2.6.1.1) : TGO : Aspartate aminotransférase (EC 2.6.1.2) ; GGT : $\gamma$-glutamyltransférase (EC 2.3.2.2).

notables de la TGO et à un bien moindre degré celles de la TGP ; on peut probablement rattacher l'hypersidérémie à ce processus ; (2) une cholestase reflétée par l'augmentation de la GGT ou des PAL ainsi que par celles de la bilirubine et du cholestérol ; (3) une possible insuffisance hépatique avec abaissement de la concentration d'albumine, des triglycérides et d'urée; il n'est pas impossible que la diminution de l'appétit contribue également à ces variations. II est particulièrement intéressant de noter que les altérations biologiques ont été également observées chez plus de la moitié des agnelles apparemment indemnes, démontrant ainsi que le seul examen clinique ne permet pas de rendre compte de l'extension de la maladie.

II apparaît que l'extension de cette intoxication ne peut être pleinement évaluée qu'avec l'aide de la biochimie sérique ; aspécifique mais très sensible, la GGT est, dans ce cadre, l'indicateur de choix ainsi que cela avait déjà été souligné (Towers et Straton, 1978).

Atherton L. G., Brewer D., Taylor A., 1974. "Pythomyces chartarum ": a fungal parameter in the etiology of some diseases of domestic animals. In Purchase, PFM, Mycotoxins. Elsevier, Amsterdam.

Bézille P., Braun J. P., Le Bars J., 1984. Première identification de l'eczéma facial chez les ovins en Europe. Rec. Méd. vét., 160, 339-347.

Riet F., Dias L. E., 1974. El hongo Pythomyces chartarum associado con casos de fotosensibilizacion hepatogene in bovinos. V/e Congr. Latinoamericano y venezolano de microbiologia, Venezuela.

Towers N. R., Straton G. C., 1978. Serum gamma-glutamyltransferase as a measure of sporidesmininduced liver damage in sheep. N. Z. vet. J., 26, 109-112. 